\title{
DOES HANDBALL THROWING VELOCITY INCREASE AFTER AN ECCENTRIC OVERLOAD-INDUCED POSTACTIVATION POTENTIATION?
}

\author{
Pablo Asencio ${ }^{1}$; Rafael Sabido ${ }^{1}$; Adrián García-Valverde ${ }^{2}$; \\ José Luis Hernández-Davó ${ }^{3}$ \\ 1. Department of Sport Sciences of Miguel Hernandez University, Spain. \\ 2. University of Almeria, Spain. \\ 3. Isabel I de Castilla International University, Spain
}

\begin{abstract}
Introduction: Post-activation performance enhancement (PAPE) has been defined as an increase in performance of voluntary movements after a high-intensity voluntary task. This phenomenon can be achieved through different strategies. However, the relationship between a conditioning eccentric overload (EO) exercise and PAPE in the upper extremities is scarce. The aim of this work was to study the application of PAPE to improve handball throwing velocity using EO, and to compare it with a traditional resistance training exercise. Material and methods: Fourteen team handball players carried out two sessions with different PAPE protocols. One of the sessions consisted of performing a PAPE protocol through a set of three repetitions at $90 \%$ of RM in the bench press (BP). In the other session, a set of three maximal-effort repetitions of one-handed horizontal press was carried out using a conical pulley (CP) with a $0.16 \mathrm{~kg} \cdot \mathrm{m}^{2}$ inertial load. Throwing velocity was measured pre and post both protocols. Results: Both protocols showed a non-significant handball throwing velocity after the application of PAPE protocols (effect size = 0.24 and 0.20 for $\mathrm{CP}$ and BP respectively). Conclusions: None of the procedures obtained the expected PAPE phenomenon for the improvement of handball throw velocity. Future studies need to assess different EO protocols to elicit PAPE in complex sport-related actions.
\end{abstract}

Keywords: post-activation potentiation enhancement, eccentric overload, conical pulley, throw, team handball

\section{¿AUMENTA LA VELOCIDAD DE LANZAMIENTO DE BALONMANO TRAS LA APLICACIÓN DE UN PROTOCOLO DE ELEVACIÓN DEL RENDIMIENTO POSTERIOR A UNA ACTIVACIÓN MEDIANTE SOBRECARGA EXCÉNTRICA?}

\begin{abstract}
RESUMEN
Introducción: la elevación del rendimiento posterior a la activación (PAPE) se ha definido como un aumento en el rendimiento de los movimientos voluntarios después de una tarea voluntaria de alta intensidad. Este fenómeno se puede lograr a través de diferentes estrategias. Sin embargo, la relación entre un ejercicio de sobrecarga excéntrica condicionada (EO) y el fenómeno de PAPE en las extremidades superiores ha sido poco estudiada. El objetivo de este trabajo fue estudiar la aplicación de PAPE para mejorar la velocidad de lanzamiento de balonmano mediante un protocolo de EO, y compararlo con un ejercicio tradicional de entrenamiento de fuerza. Material y métodos: Catorce jugadores de balonmano realizaron dos sesiones con diferentes protocolos PAPE. Una de las sesiones consistió en realizar un protocolo PAPE que consistía en tres repeticiones al $90 \%$ de RM en el press de banca (BP). En la otra sesión, se realizó una serie de tres repeticiones de máxima intensidad del ejercicio de press horizontal a una mano utilizando una polea cónica (CP) con una carga inercial de $0.16 \mathrm{~kg} \bullet \mathrm{m} 2$. La velocidad de lanzamiento se midió antes y después de ambos protocolos. Resultados: Ninguno de los protocolos consiguió un aumento significativo de la velocidad de lanzamiento después de la aplicación de ambos protocolos PAPE (tamaño del efecto = 0.24 y 0.20 para CP y BP respectivamente). Conclusiones: Ninguno de los procedimientos obtuvo el fenómeno PAPE esperado para la mejora de la velocidad de lanzamiento de balonmano. Futuros
\end{abstract}


estudios necesitan evaluar diferentes protocolos de EO para obtener PAPE en acciones complejas vinculadas con el rendimiento deportivo.

Palabras clave: elevación del rendimiento posterior a la activación, sobrecarga excéntrica, polea cónica, lanzamiento, balonmano

\section{Correspondence:}

José Luis Hernández-Davó

Isabel I de Castilla International University, Spain.

jlhdez43@gmail.com

Submitted: $27 / 03 / 2020$ 


\section{INTRODUCTION}

Athletes' ability to generate maximal muscular force and power is essential for succeed in many explosive sports, such as team sports, track and field events, racket sports, etc. Several authors have shown that strategies eliciting post-activation potentiation (PAP) can increase physical performance acutely over time and, consequently, improve athlete performance (Blazevich and Babault, 2019; Cuenca-Fernández, López-Contreras and Arellano, 2015; Cuenca-Fernández, Ruiz-Teba, López-Contreras and Arellano, 2018; Crewther et al., 2011; Healy and Comyns, 2017; de Hoyo et al., 2015). According to several authors, it is possible to cause an increase in muscle performance after a maximal or submaximal contraction, including greater twitch force, rate of force development and power production following post-activation potentiation (PAP) warm-up protocols (Barbosa, Barroso and Andries, 2015; de Hoyo, Sañudo, Pradas and Carrasco, 2014; Tillin and Bishop, 2009; Wilson et al., 2013).

The mechanisms underlying the PAP phenomenon are not fully known yet, however, some of them have already been identified. According to Tillin and Bishop (2009), one of them are the increases in calcium sensitivity as a consequence of a greater concentration of the myosin light chain kinase enzyme that catalyses phosphorylation. In addition, increases in the number of neurotransmitters and their effectiveness, would favour the increase of the fast fibres' recruitment. Finally, muscle mechanics, such as the pennation angle, decreases with respect to its baseline situation after a contraction, providing mechanical advantages related to the transmission of forces to the tendon (Tillin and Bishop, 2009). Altogether, these mechanisms have been shown to modify muscle properties (e.g. RFD, twitch force increases). Nevertheless, from a practical point of view, it is more interesting to know if these mechanisms would transfer to performance increases in sport-related actions (e.g. jumping, kicking, throwing). The phenomenon causing an enhancement in voluntary muscular performance after a high-intensity voluntary conditioning activity, without confirmatory evidence of classical PAP (e.g. twitch force assessment) has been recently defined as post-activation performance enhancement (PAPE) (Cuenca-Fernández et al., 2017).

However, there are, at least, two limiting factors at the time of the production of PAPE, being the fatigue (Requena et al., 2011) and the training level (Wilson et al., 2013) the most common. Both factors are related, as at the end of the contraction, the athlete could be fatigued, especially in the first stages of recovery. Although the previous muscular contraction maintains the modulating processes of PAPE elevated, there is also a high level of simultaneous fatigue that will affect performance. In addition, Chistros (2010) observed that the optimal time for the optimization of PAPE ranges between 
five and twenty minutes after performing the previous contraction. Further, several studies have determined that applying the PAPE phenomenon in untrained subjects could deteriorate their performance more than improve it (Batista, Roschel, Barroso, Ugrinowitsch and Tricoli, 2011; Barbosa et al., 2015).

Nevertheless, when the conditioning task is correctly implemented, PAPE can be equally achieved through protocols using different contraction-types. (Cuenca et al., 2015; Cuenca et al., 2016; Seitz and Half, 2016; Yustres-Amores, Rave, Castellanos, Rico and Abellá, 2015; Barbosa, Raboso and Andries, 2015; Tillin and Bishop, 2009). Thus, Rixon, Lamont and Bemben (2007) found greater PAPE in the countermovement jump (CMJ) after isometric actions compared with heavy dynamic contractions. Contrarily, Dechechi, Lopes, Galatti and Ribeiro (2013) showed the greater PAPE effects following high-load concentric actions, while Golas, Mazczyk, Zajac, Milkolajec and Stastny (2016) reported the higher PAPE after supramaximal eccentric actions. From the last study, it could be concluded that high-intensity eccentric actions are useful to cause PAPE.

In the last few years, isoinertial devices have emerged as an effective way to generate greater eccentric than concentric force production (eccentric overload; EO). EO devices are increasing its popularity in both sports training and physical rehabilitation fields. It consists in applying force to pull a rope which is wound around a rotating base. After the rope unwinds completely, the structure will begin to rotate in the opposite direction to rewind the rope, maintaining the inertia generated during the concentric phase. When performing the braking action correctly (i.e. delaying it to the last part of the eccentric phase), isoinertial devices allow the achievement of EO values. Among the different EO devices we can find conical pulleys, which allow a high variability of multidirectional movements with allow to perform highly specific resistance training movements (Tous-Fajardo, Gonzalo-Skok, Arjol-Serrano and Tesch, 2016).

A great amount of research has shown the effectiveness of EO to improve muscular strength and hypertrophy, and tendon adaptations faster than traditional resistance training (Norrbrand, Fluckey, Pozzo, and Tesch, 2008; Friedmann-Bette et al., 2008). Nevertheless, the relationship between EO and PAPE production has received little attention, especially regarding upper-body exercises. Relative to PAPE after lower-limb EO exercises, research has shown its efficacy, reporting increases in CMJ and change of direction performance after a warm-up protocol including flywheel squats (Beato, Stiff and Coratella, 2019; De Hoyo et al., 2014). In addition, performance improvements during more specific movements (swimming start) were reported by Cuenca et al., (2019) following a flywheel squat warm-up protocol. To date, only one previous study (Cuenca-Fernández et al., 2018) has assessed the PAPE effects 
after an upper-body EO exercise, showing similar results in swimming performance improvements following both EO and heavy-load warm-up protocols.

Due to the scarcity of research about PAPE in functional upper-body movements using flywheel devices, the aim of this study was to assess the usefulness of an EO conditioning protocol to produce PAPE, and to compare this methodology with a more traditional PAPE protocol based on a heavy-load traditional resistance exercise. The hypothesis is that both procedures would be equally useful to produce PAPE.

\section{METHOD}

\section{Participants}

Fourteen physically trained men belonging to an amateur handball team took part in the study (age $=23.76 \pm 3.72$ years; height $=1.82 \pm 0.08 \mathrm{~m}$; body mass $=81.79 \pm 8.90 \mathrm{~kg} ; 1 \mathrm{RM}$ bench press $=88.64 \pm 12.52 \mathrm{~kg}$; ratio $1 \mathrm{RM} /$ body mass $=1.08 \pm 0.19$ ). Participants reported at least 8-years' experience in handball training. All participants were following a 4 days/week training program that includes systematic strength training sessions. Each participant gave his written consent to participate in this study, having previously been informed of the characteristics and the risks of the study. This study was approved by the Ethics Committee of the University in accordance with the Declaration of Helsinki.

\section{Procedures}

The study followed a quasi-experimental design, with a counterbalanced protocol. The measurements took place in two different sessions and were preceded by two familiarization sessions. In the familiarization sessions the athletes learned how to carry out the exercise with the conical pulley to produce the greatest possible EO, and the $1 \mathrm{RM}$ in the bench press exercise was recorded. The testing sessions of both PAPE protocols began three days after the familiarization sessions. In each session a different PAPE protocol was performed, preceded by a general warm-up consisting of activation by light jogging, twelve repetitions of dynamic stretching in different planes of movement, a series of core exercises, ten push-ups, ten passes from a distance of ten meters and ten throws at submaximal speed from a distance of nine meters (Figure 1). Throwing velocity was assessed by measuring eight maximal-intended velocity overarm throws. In one of the sessions, three repetitions with $90 \% 1 \mathrm{RM}$ of a free-weight bench press at maximum speed were carried out to produce the PAPE effect. The bench press exercise was chosen because it elicits the activation of the primary upper-body muscles involved in the throwing action (pectoralis, triceps, deltoid) (Rousanoglu, 
Noutsos, Bayios and Boudolos, 2014). In addition, this exercise is usually included within handball players training programs, and significant positive correlations between bench press strength and throwing velocity have been previously reported (Marques, Van Den Tillaar, Vescovi \& González-Badillo, 2007). The other session was conducted using the EO protocol, performing six repetitions, being the first three to increase the velocity and then three maximal-effort repetitions, using a moment of inertia of $0.16 \mathrm{~kg} \cdot \mathrm{m}^{2}$. In both sessions, regardless of the PAPE protocol that was applied (bench press or conical pulley), there was a four-minute break prior to both pre- and post-test, (Healy and Comyns, 2017; Nibali et al., 2015; Wilson et al., 2013). The session order was balanced among participants to avoid any fatigue or learning effect.

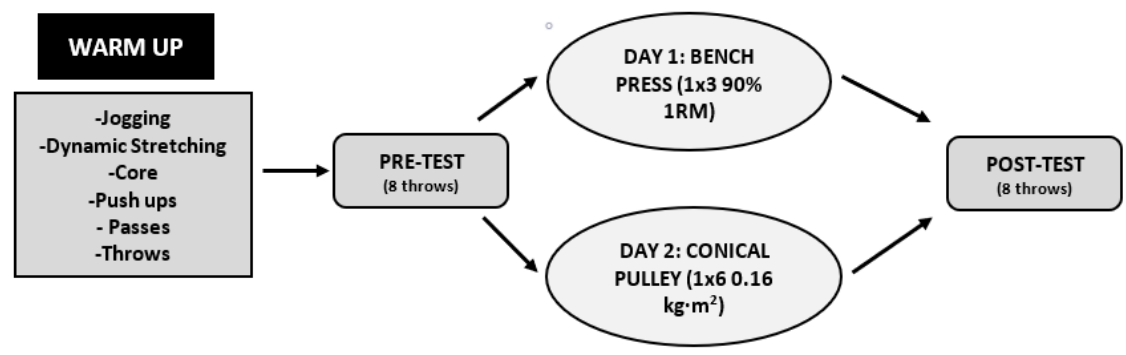

FIGURE 1: Schedule of the procedures for both PAPE protocols.

\section{Measurements and instruments}

Throwing velocity. The throws were made with a size three team handball ball, with a pressure of 0.16 bars. The throws were performed from a $9 \mathrm{~m}$ distance and using a standing position, placing the opposite foot to the throwing arm forward. Ball speed was measured with a radar gun from Sports Radar (model SR 3600, LTD of Homosassa, Florida) located one meter behind the goal. The analysis of throwing velocity is justified by its relationship with handball success (Ortega-Becerra Pareja-Blanco, Jiménez-Reyes, CuadradoPeñafiel and González-Badillo, 2018).

$1 R M$ bench press. The $1 \mathrm{RM}$ was assessed during the first session by means of a linear transducer (T-Force System, Ergotech, Murcia, Spain). A recording of the $1 \mathrm{RM}$ of the free weight bench press, performed with an Olympic bar, was measured using the T-Force software. Participants performed the exercise lying on a bench in supine position, lowering the bar to approximately two centimetres from their breastplate, and then lifting the bar until completing the elbow extension. The repetition maximum was checked by the movement velocity, considering a repetition maximum when the velocity was lower to 0.2 $\mathrm{m} \cdot \mathrm{s}^{-1}$ (Sánchez-Medina, Pérez and González Badillo, 2010). During both 1RM 
testing and bench press protocol, participants were instructed to perform the concentric phase of the movement as fast as possible.

Eccentric overload. The isoinertial device used in the present study was a conical pulley (Versa-Pulley, Costa Mesa, CA). In the present study, twelve 0.68 $\mathrm{kg}$ weights were used, with a total inertia of $0.163 \mathrm{~kg} \cdot \mathrm{m}^{2}$. The weights were screwed to the base of the pulley, which was 40 centimetres in diameter. The dimensions of the cylindrical cone were 14 centimetres in diameter in its widest part and 2.5 centimetres in its narrowest part and the total height was of $27.5 \mathrm{~cm}$. The conditioning exercise to produce PAPE was performed in a standing position, advancing the lower extremity contrary to the push arm, which started from an elbow abduction and flexion position, both at $90^{\circ}$. After finishing the concentric phase, the eccentric phase was carried out with a combination of adduction and shoulder flexion above the head simulating the movement pattern of arming and performing a throw in handball. The rope was three meters long and it was placed two meters above ground level. During each repetition, players were fully encouraged to perform the concentric phase of the movement as fast as possible, and to delay the braking action until the last part of the eccentric phase.

\section{Statistical analysis}

The SPSS (version 23.0) statistical package was used for the data analysis. With the data from the pre- and post- application tests of the PAPE protocols, a paired T-test was performed. Statistical significance was set at $\mathrm{p}<.05$. In addition, the effect size (ES) was calculated through Cohen's $d$, and interpreted using the Rhea criteria (2004) for sports samples. Thus, according to Rhea's (2004) characterization of "recreational athletes" (those between 1- and 5years' experience in strength training), ES was interpreted as trivial $<0.35$, small 0.35-0.8, moderate 0.8-1.5 and large > 1.5. Finally, Pearson's correlation coefficient ( $r$ ) was used to assess the potential relationships between the participants' strength level and throwing velocity data.

\section{RESULTS}

The paired T-test showed non-significant changes in throwing velocity after either the bench press $\left(\mathrm{T}_{(13,1)}=1.82, \mathrm{p}=.091\right)$ and the conical pulley $\left(\mathrm{T}_{(13,1)}\right.$ $=1.75, \mathrm{p}=.103$ ) PAPE protocols. The individual responses after each protocol are shown in the Table 1 . Both protocols entailed a very similar $\%$ of change (3.4-3.8\%) and the same number of positive/negative responses (11/3). In addition, the calculated effect size was trivial for both the bench press $(d=0.20$, trivial), and the conical pulley protocol ( $d=0.24$; trivial). 
Individual changes in throwing velocity after both PAPE protocols.

\begin{tabular}{ccccccc}
\hline \hline & \multicolumn{3}{c}{ BENCH PRESS } & \multicolumn{3}{c}{ CONICAL PULLEY } \\
\hline \multirow{2}{*}{ PARTICIPANT } & $\begin{array}{c}\text { TVpre } \\
(\mathrm{km} / \mathrm{h})\end{array}$ & $\begin{array}{c}\text { TVpost } \\
(\mathrm{km} / \mathrm{h})\end{array}$ & Change $(\%)$ & $\begin{array}{c}\text { TVpre } \\
(\mathrm{km} / \mathrm{h})\end{array}$ & $\begin{array}{c}\text { TVpost } \\
(\mathrm{km} / \mathrm{h})\end{array}$ & Change $\%)$ \\
\hline 1 & 80.8 & 79.8 & $-1.24 \%$ & 82.4 & 83.0 & $0.73 \%$ \\
2 & 81.4 & 82.6 & $1.47 \%$ & 79.4 & 80.8 & $1.76 \%$ \\
3 & 84.6 & 86.2 & $1.89 \%$ & 82.4 & 84.6 & $2.67 \%$ \\
4 & 73.6 & 75.2 & $2.17 \%$ & 72.0 & 76.2 & $5.83 \%$ \\
5 & 78.2 & 71.8 & $-8.18 \%$ & 74.0 & 74.0 & $0.00 \%$ \\
6 & 68.8 & 71.0 & $3.20 \%$ & 67.0 & 70.4 & $5.07 \%$ \\
7 & 80.4 & 83.0 & $3.23 \%$ & 85.0 & 82.8 & $-2.59 \%$ \\
8 & 70.4 & 76.0 & $7.95 \%$ & 79.2 & 80.4 & $1.52 \%$ \\
9 & 80.6 & 83.8 & $3.97 \%$ & 77.8 & 85.0 & $9.25 \%$ \\
10 & 62.6 & 62.2 & $-0.64 \%$ & 75.0 & 73.0 & $-2.67 \%$ \\
11 & 73.0 & 73.0 & $0.00 \%$ & 77.4 & 77.8 & $0.52 \%$ \\
12 & 82.0 & 87.6 & $6.83 \%$ & 91.6 & 89.0 & $-2.84 \%$ \\
13 & 81.4 & 83.4 & $2.46 \%$ & 82.8 & 84.2 & $1.69 \%$ \\
14 & 80.0 & 82.4 & $3.00 \%$ & 81.2 & 84.0 & $3.45 \%$ \\
\hline \hline
\end{tabular}

TVpre $=$ Throwing velocity pre; TVpost $=$ Throwing velocity post

The correlation analysis showed non-significant relationships between the strength-related variables and throwing velocity data (Table 2).

TABLE 2

Correlation analysis between strength values handball throwing velocity variables.

\begin{tabular}{cccc}
\hline \hline & $\begin{array}{c}\text { Throwing } \\
\text { velocity }\end{array}$ & $\begin{array}{c}\text { Change after BP } \\
\text { protocol }\end{array}$ & $\begin{array}{c}\text { Change after CP } \\
\text { protocol }\end{array}$ \\
\hline 1RM & .406 & .127 & .026 \\
1RM/body weight & .366 & .061 & .336 \\
\hline \hline
\end{tabular}

\section{DISCUSSION}

The aim of this study was to compare two PAPE protocols aiming to increase handball throwing velocity. The main finding of the present study was, that in a sample of amateur handball players, neither the heavy load nor the EO procedure entailed statistically significant positive PAPE effects in throwing velocity.

The athletes' strength level has been previously suggested as a key factor for PAPE effects (Seitz and Haff, 2015; Wilson et al., 2013). In line with this, Cuenca-Fernández, Taladriz, López-Contreras, de la Fuente, Argüelles and Arellano (2015) showed that positive PAPE effects after a conditioning EO exercise were dependent on the athletes' strength level (1RM/BW), with the stronger athletes showing the greater benefits. In another study, YustresAmores et al., (2015) compared a PAPE protocol using the traditional squat exercise with another squat protocol performed on an isoinertial device, 
reporting no performance differences between swimmers in different types of jump (CMJ, SJ and Abalakov). The maximum strength level of the sample in that study, similar than in the present study, did not reach the average values of trained subjects. In a former meta-analysis, Seitz and Haff (2015) considered strong participants those with a 1RM/BW in the bench press greater than 1.35 . In such meta-analysis, weaker athletes (< 1.35 1RM/BW) showed lower benefits of conditioning exercises aiming to produce PAPE, reporting an ES of 0.32 , which is similar to the ES found in the present study $(0.20-0.24)$. The low levels of relative strength of the sample in our study $(1 \mathrm{RM} / \mathrm{BW}=1.08)$ may explain why the participants in the current study did not obtain significant benefits from the conditioning exercises. This fact has been previously stated, since the lower the strength level of the athlete is, the greater the fatigue generated, and therefore, the lower likelihood of PAPE effects. Further, the correlation analysis showed no significant relationships between strength variables and PAPE effects. It should be noted the homogeneity of our sample, where only one participant had a 1RM/BW to be considered a strong individual ( $>$ 1.35). Consequently, it is reasonable that the correlation analysis in the present study did not reach any significant relationship.

Another variable that influences PAPE responses is the recovery time after the conditioning exercise. Thus, Ulrich and Parstorfer (2017), compared PAPE effects at different recovery period times (1, 4, 8, 12 and $16 \mathrm{~min}$ ) after an upper-body conditioning exercise, showing only positive effects 8 minutes after. Regarding EO conditioning tasks, Cuenca et al., (2015) carried out the comparison between four lunge repetitions in the Smith machine at $85 \%$ of $1 \mathrm{RM}$ and four lunge repetitions with an isoinertial device, obtaining greater improvements in the swimming diving start after the EO protocol. In that study, Cuenca et al., (2015) used 8-minute rest intervals. To the best of authors' knowledge, in the unique study involving upper-body EO exercises as a conditioning task (Cuenca et al., 2017) positive PAPE effects in swimming performance were found when using a 6-minute rest interval. In this line, Seitz and Haff (2015) reported in their meta-analysis that long rest-intervals $(>4$ min) are more likely to produce PAPE effects compared with shorter (3 to 4 $\min$ ) recovery periods. Therefore, the short rest period (4 min) used in the present study, may had not allowed for a complete recovery from the conditioning task, which could have hidden a significant positive PAPE effect.

Both exercise intensity and volume are also important to elicit PAPE responses (Wilson et al., 2013). In relation to the exercise intensity, in the present study, the EO protocol was performed with an inertial load of 0.16 $\mathrm{kg} \cdot \mathrm{m}^{2}$, being similar to the $0.20 \mathrm{~kg} \cdot \mathrm{m}^{2}$ used by Beato, Stiff and Coratella (2019), which showed positive PAPE effects in the vertical jump exercise. Unfortunately, Cuenca-Fernández et al., (2018) did not report the inertial load used for their 
upper-body EO conditioning protocol. For the bench press protocol, it is difficult to conclude if the $90 \% 1 \mathrm{RM}$ intensity is the most appropriate, as a meta-analysis (Wilson et al., 2013) suggested moderate loads ( $<65 \% 1 \mathrm{RM}$ ) a better choice, while in other meta-analysis, Seitz and Haff (2015) showed better results after conditioning protocols using high loads. Regarding the volume used in the present study, the three repetitions performed during the EO protocol implied the same volume that the unique upper-body EO conditioning protocol found in the literature (Cuenca-Fernández et al., 2018). However, derived from the low strength level of the participants in the present study, it is possible that multiple- instead of a single-set of conditioning activity would have been more appropriate (de Keijzer, McErlain-Naylor, Dello-Iacono and Beato, 2020; Seitz and Haff, 2015).

There are also additional variables that may have influenced the results of the present study. One of them is the individualization of the load during EO protocols. In fact, in some studies (de Hoyo et al., 2014; Timon et al., 2019) the EO protocol was carried out with the inertial load eliciting the individuals' highest power values, showing these works positive PAPE effects. Contrarily, including the present work, other studies (Cuenca-Fernández et al., 2018; Dobbs, Tolusso, Fedewa and Esco, 2019) did not use the peak power load, but the same inertial load for all the subjects. Therefore, this fact may be partly responsible for the non-significant PAPE effects found and could be consider as a limitation of the present work. Finally, it should be highlighted the nature of the handball throwing technique, a movement that involved a whole-body action in a proximal-to-distal sequence. Therefore, it is possible that this complex movement requires a different conditioning stimulus to elicit PAPE responses.

\section{CONCLUSIONS}

The results of the present study suggested that neither the bench press nor the EO conditioning protocols led to significant increases in handball throwing velocity. However, both protocols caused a slightly increase in throwing speed, and therefore, could be considered during handball warm-up routines. The potential mechanisms explaining the non-significant PAPE responses found in the present study include the relative low strength level of the athletes, and the short rest period ( $4 \mathrm{~min}$ ) allowed after the conditioning protocols.

\section{REFERENCES}

Anthi, X., Dimitrios, P., \& Christos, K. (2014). On the mechanisms of postactivation potentiation: the contribution of neural factors. Journal of Physical Education and Sport, 14(2), 134. doi: 10.7752/jpes.2014.02021 
Barbosa, A. C., Barroso, R., \& Andries, O. (2015). Post-activation potentiation in propulsive force after specific swimming strength training. International Journal of Sports Medicine, 37(4), 313-7. doi: 10.1055/s-0035-1565050

Batista, M. A., Roschel, H., Barroso, R., Ugrinowitsch, C., \& Tricoli, V. (2011). Influence of strength training background on postactivation potentiation response. The Journal of Strength and Conditioning Research, 25(9), 24962502. doi: 10.1519/JSC.0b013e318200181b.

Beato, M., Stiff, A., \& Coratella, G. (2019). Effects of postactivation potentiation after an eccentric overload bout on countermovement jump and lower-limb muscle strength.Journal of Strength and Conditioning Research. doi: 10.1519/JSC.0000000000003005

Blazevich, A. J., \& Babault, N. (2019). Post-activation Potentiation (PAP) versus post-activation performance enhancement (PAPE) in humans: historical perspective, underlying mechanisms, and current issues. Frontiers in Physiology, 10, 1359. doi: 10.3389/fphys.2019.01359

Christos, K. (2010). Post-activation potentiation: Factors affecting it and the effect on performance. Journal of Physical Education and Sport, 28(3).

Crewther, B. T., Kilduff, L. P., Cook, C. J., Middleton, M. K., Bunce, P. J., \& Yang, G. Z. (2011). The acute potentiating effects of back squats on athlete performance. The Journal of Strength and Conditioning Research, 25(12), 3319-3325. doi: 10.1519/JSC.0b013e318215f560

Cuenca-Fernández, F., López-Contreras, G., \& Arellano, R. (2015). Effect on swimming start performance of two types of activation protocols: lunge and YoYo squat. The Journal of Strength and Conditioning Research, 29(3), 647655. doi: 10.1519/JSC.0000000000000696

Cuenca-Fernández, F., López-Contreras, G., Mourão, L., de Jesus, K., de Jesus, K., Zacca, R., ... \& Arellano, R. (2019). Eccentric flywheel post-activation potentiation influences swimming start performance kinetics. Journal of Sports Sciences, 37(4), 443-451. doi: 10.1080/02640414.2018.1505183

Cuenca-Fernández, F., Ruiz-Teba, A., López-Contreras, G., \& Arellano, R. (2018). Effects of two types of activation protocols based on post-activation potentiation on 50-meter freestyle performance. Journal of Strength and Conditioning Research. doi:10.1519/JSC.0000000000002698

Cuenca-Fernández, F., Smith, I. C., Jordan, M. J., MacIntosh, B. R , LopezContreras, G., Arellano, R., \& Herzoz W. (2017). Nonlocalized postactivation performance enhancement (PAPE) effects in trained athletes: a pilot study. Applied Physiology, Nutrition, and Metabolism, 42(10), 1122-5. doi: 10.1139/apnm-2017-0217.

Cuenca-Fernández, F., Taladriz, S., López-Contreras, G., de la Fuente, B., Argüelles, J., \& Arellano, R. (2015). Relative force and PAP in swimming start performance. ISBS, Conference Proceedings Archive. 
de Hoyo, M., de la Torre, A., Pradas, F., Sañudo, B., Carrasco, L., Mateo-Cortes, J., et al. (2015). Effects of eccentric overload bout on change of direction and performance in soccer players. International Journal of Sports Medicine, 36(4), 308-314. doi: 10.1055/s-0034-1395521

Dechechi, C., Lopes, C., Galatti, L. R., \& Ribeiro, R. (2013). Post activation potentiation for lower limb with eccentric and concentric movements on sprinters. International Journal Sports Science,3(1), 1-3. doi: 10.5923/j.sports.20130301.01

De Keijzer, K. L., McErlain-Naylor, S. A., Dello-Iacono, A., \& Beato, M. (2020). Effect of volume on eccentric overload-induced postactivation potentiation of jumps. International Journal of Sports Physiology and Performance, 28: 1-6. doi: 10.1123/ijspp.2019-0411

Dobbs, W. C., Tolusso, D. V., Fedewa, M. V., \& Esco, M. R. (2019). Effect of postactivation potentiation on explosive vertical jump: A systematic review and meta-analysis. The Journal of Strength and Conditioning Research, 33(7), 2009-2018. doi: 10.1519/JSC.0000000000002750

Friedmann-Bette, B., Bauer, T., Kinscherf, R., Vorwald, S., Klute, K., Bischoff, D., et al. (2010). Effects of strength training with eccentric-overload on muscle adaptation in male athletes. European Journal of Applied Physiology, 108(4), 821-836. doi: 10.1007/s00421-009-1292-2

Gołaś, A., Maszczyk, A., Zajac, A., Mikołajec, K., \& Stastny, P. (2016). Optimizing post activation potentiation for explosive activities in competitive sports. Journal of Human Kinetics, 52(1), 95-106. doi: 10.1515/hukin-20150197

Hamada, T., Sale, D. G., MacDougall, J. D., \& Tarnopolsky, M. A. (2000). Postactivation potentiation, fiber type, and twitch contraction time in human knee extensor muscles. Journal of Applied Physiology, 88(6), 21312137. doi: 10.1152/jappl.2000.88.6.2131

Healy, R., \& Comyns, T. M. (2017). The application of postactivation potentiation methods to improve sprint speed. Strength and Conditioning Journal, 39(1), 1-9. doi: 10.1519/SSC.0000000000000276

Mahlfeld, K., Franke, J., \& Awiszus, F. (2004). Postcontraction changes of muscle architecture in human quadriceps muscle. Muscle \& Nerve, 29(4), 597-600. doi: $10.1002 /$ mus. 20021

Marques, M. C., van der Tillar, R., Vescovi, J. D., González-Badillo, J. J. (2007). Relationships between throwing speed, muscle power, and bar velocity during bench press in elite handball players. International Journal of Sports Physiology and Performance, 2(4), 414-422. doi: 10.1123/ijspp.2.4.414

Nibali, M. L., Chapman, D. W., Robergs, R. A., \& Drinkwater, E. J. (2015). Considerations for determining the time course of post-activation 
potentiation. Applied Physiology, Nutrition, and Metabolism, 40(11), 11631170.doi: 10.1139/apnm-2015-0175

Norrbrand, L., Fluckey, J. D., Pozzo, M., \& Tesch, P. A. (2008). Resistance training using eccentric overload induces early adaptations in skeletal muscle size. European Journal of Applied Physiology,102(3), 271-281. doi: 10.1007/s00421-007-0583-8

Ortega-Becerra, M., Pareja-Blanco, F., Jiménez-Reyes, P., Cuadrado-Peñafiel, V., \& González-Badillo, J. J. (2018). Determinant factors of physical performance and specific throwing in handball players of different ages. Journal of Strength and Conditioning Research, 32(6), 1778-1786. doi: 10.1519/JSC.0000000000002050

Requena, B., de Villarreal, E. S. S., Gapeyeva, H., Ereline, J., García, I., \& Pääsuke, M. (2011). Relationship between postactivation potentiation of knee extensor muscles, sprinting and vertical jumping performance in professional soccer players. The Journal of Strength and Conditioning Research, 25(2), 367-373. doi: 10.1519/JSC.0b013e3181be31aa

Rhea, M. R. (2004). Determining the magnitude of treatment effects in strength training research through the use of the effect size. The Journal of Strength and Conditioning Research, 18(4), 918-920. doi: 10.1519/14403.1

Rixon, K. P., Lamont, H. S., \& Bemben, M. G. (2007). Influence of type of muscle contraction, gender, and lifting experience on postactivation potentiation performance. Journal of Strength and Conditioning Research, 21(2), 500. doi: 10.1519/R-18855.1

Sanchez-Medina, L., Perez, C. E., \& Gonzalez-Badillo, J. J. (2010). Importance of the propulsive phase in strength assessment. International Journal of Sports Medicine, 31(02), 123-129. doi: doi: 10.1055/s-0029-1242815

Seitz, L. B., \& Haff, G. G. (2016). Factors modulating post-activation potentiation of jump, sprint, throw, and upper-body ballistic performances: A systematic review with meta-analysis. Sports Medicine,46(2), 231-240. doi: 10.1007/s40279-015-0415-7.

Tillin, M. N. A., \& Bishop, D. (2009). Factors modulating post-activation potentiation and its effect on performance of subsequent explosive activities. Sports Medicine, 39(2), 147-166. doi: 10.2165/00007256-20093902000004

Timon, R., Allemano, S., Camacho-Cardeñosa, M., Camacho-Cardeñosa, A., Martinez-Guardado, I., \& Olcina, G. (2019). Post-activation potentiation on squat jump following two different protocols: Traditional vs. inertial flywheel. Journal of Human Kinetics, 69, 271-281. doi: 10.2478/hukin-20190017

Tous-Fajardo, J., Gonzalo-Skok, O., Arjol-Serrano, J. L., \& Tesch, P. (2016). Enhancing change-of-direction speed in soccer players by functional inertial 
eccentric overload and vibration training. International Journal of Sports Physiology and Performance, 11(1), 66-73. doi: 10.1123/ijspp.2015-0010

Tsoukos, A., Brown, L. E., Veligekas, P., Terzis, G., \& Bogdanis, G. C. (2019). Postactivation potentiation of bench press throw performance using velocity-based conditioning protocols with low and moderate loads. Journal of Human Kinetics, 68, 81-98. doi: 10.2478/hukin-2019-0058

Ulrich, G., \& Parstorfer, M. (2017). Effects of plyometric versus concentric and eccentric conditioning contractions on upper-body postactivation potentiation. International Journal of Sports Physiology and Performance, 12(6), 736-741. doi: 10.1123/ijspp.2016-0278

West, D. J., Cunningham, D. J., Crewther, B. T., Cook, C. J., \& Kilduff, L. P. (2013). Influence of ballistic bench press on upper body power output in professional rugby players. The Journal of Strength and Conditioning Research, 27(8), 2282-2287. doi: 10.1519/JSC.0b013e31827de6f1

Wilson, J. M., Duncan, N. M., Marin, P. J., Brown, L. E., Loenneke, J. P., Wilson, S. M., et al. (2013). Meta-analysis of postactivation potentiation and power: effects of conditioning activity, volume, gender, rest periods, and training status. The Journal of Strength and Conditioning Research, 27(3), 854-8. doi: 10.1519/JSC.0b013e31825c2bdb

Yustres-Amores, I, Ravé, J. M. G., Castellanos, R. B., Rico, B. C., \& Abellá, C. P. (2015). Variaciones del rendimiento en la salida de natación mediante la respuesta aguda a diferentes protocolos de entrenamiento (tradicional o máquina isoinercial). Revista Española de Educación Física y Deportes, (411), 23-4. doi: 10.13140/RG.2.1.1091.4642 